\section{Insect bites make viral disease worse}

Bites from mosquitoes that spread viruses trigger a distinct immune response in the skin after they bite, which increases the severity of infection caused by the transmitted virus.

Clive McKimmie at the University of Leeds, UK, and his colleagues injected mice with one of two mosquitoborne viruses. Mice that were bitten by virus-free mosquitoes and then injected with the microbe showed an immune response that retained more virus at infection sites than did infected mice that had not been bitten. Immune cells called neutrophils were drawn to the bite, where they enhanced the virus's ability to infect and multiply, causing more-severe disease.

Blocking certain immune cells from reaching the site of an insect bite reduces viral replication and could be a way to diminish disease after a bite, the authors say.

Immunity 44, 1455-1469 (2016)

\section{BEHAVIOUR}

\section{Older monkeys} socialize less

Like humans, some monkeys show declining social activity with age.

Laura Almeling at the German Primate Center in Göttingen, Germany, and her colleagues studied Barbary macaques (Macaca sylvanus; pictured), and found that older females spent less time grooming others and interacted with fewer animals than

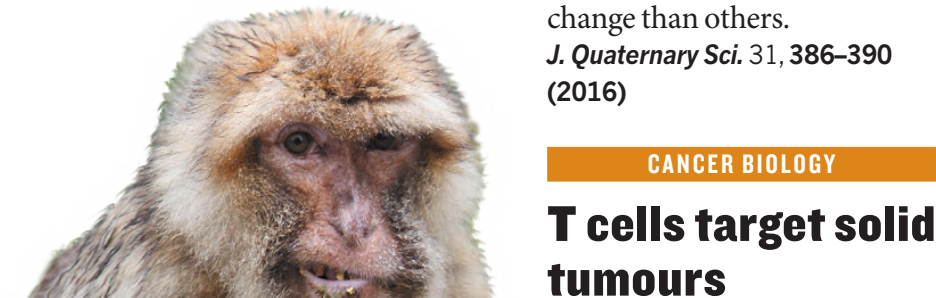

treat blood cancers has been adapted to attack solid human tumours implanted into mice.

Engineered T cells are designed to home in on specific proteins on the surface of cancer cells in the blood - but adenocarcinomas, a common type of solid tumour, rarely carry such markers. Avery Posey and Carl June of the University of Pennsylvania in Philadelphia and their colleagues developed a way to modify human T cells so that they recognize abnormal forms of a sugar molecule linked to a cell-surface protein that is abundant in many cancers. The authors found that in a mouse model of human pancreatic adenocarcinoma, all animals treated with these $T$ cells survived until the end of the experiment, compared with only $40 \%$ of untreated

THS UEK

A cancer therapy that uses genetically modified versions of patients' immune cells to controls.

Protein-linked sugars are a promising target for cancer immunotherapy, the team says. Immunity 44, 1444-1454 (2016)

warming climate by using water more efficiently.

Iain Robertson of Swansea

University, UK, and his colleagues collected a small number of samples from three tree species in Ethiopia, Namibia and South Africa, covering a small area of the continent. By measuring the ratio of carbon isotopes in each tree ring, the team estimated the water-use efficiency of the trees from 1909 to 2003. They found that two of the three species increased their wateruse efficiency - by an average of $25 \%$ - over the period.

Using water more sparingly may help to compensate for the predicted decreases in rainfall in Africa, allowing some plants to cope better with climate

\section{African trees cope with warming}

\section{EVOLUTION \\ When pupfish got to Devils Hole}

A rare fish species living in an isolated cavern pool probably originated when the cavern first opened to the surface around 60,000 years ago.

The Devils Hole pupfish (Cyprinodon diabolis) is one of the world's rarest animals, and researchers debate whether humans introduced the fish to the pool in Devils Hole in the southwestern United States between 20,000 and 10,000 years ago. İsmail Sağlam and Michael Miller at the University of California, Davis, and their colleagues analysed the genomes of the fish and two related pupfish species, and concluded that the Devils Hole pupfish became an isolated population in the cavern roughly 60,000 years ago.

A geological event may have both opened up the cavern and introduced the pupfish into it, the authors suggest.

Mol. Ecol. http://doi.org/bj78

(2016)
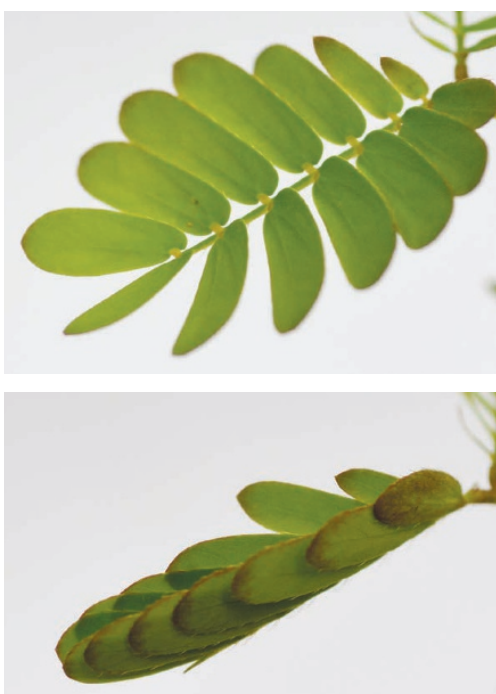

\section{MATERIALS}

\section{Self-folding mimosa mimic}

A bilayered material can curl itself into a cylinder in response to a stimulus, mimicking the leaves of the plant Mimosa pudica, which quickly fold up when lightly touched (pictured).

Zuankai Wang at the City University of Hong Kong, Antonio Tricoli at Canberra's Australian National University and their team were inspired by the plant. They adhered a hydrophobic layer, polyvinyl chloride, to a hydrophilic one, polycaprolactone, then placed this bilayer on a flexible plastic substrate before cutting the resulting trilayer into a long, thin strip. When they placed a water droplet on one end of the hydrophilic side, the two sides of the strip quickly peeled away from the substrate and wrapped around the droplet. As the water spread down the strip, the bilayer's edges curled with it to form a tube.

Such a material, which can be cut into different shapes, could one day be useful in sensors and other devices that don't require power.

Sci. Adv. 2, e1600417 (2016)

\section{$\rightarrow$ NATURE.COM}

For the latest research published by Naturevisit:

www.nature.com/latestresearch 